\title{
Dietary zinc intake is inversely related to subclinical atherosclerosis measured by carotid intima-media thickness
}

\author{
Yoon Jung Yang ${ }^{1}$, Bo Youl Choi ${ }^{1}$, Byung-Yeol Chun ${ }^{2}$, Sun-Seog Kweon ${ }^{3}$, Young-Hoon Lee ${ }^{4}$, \\ Phil Sook Park ${ }^{5}$ and Mi Kyung Kim ${ }^{1 *}$ \\ ${ }^{1}$ Department of Preventive Medicine, Medical School Building A-Room 512, College of Medicine, Hanyang University, \\ 17 Haengdang Dong, Sungdong Gu, Seoul 133-791, South Korea \\ ${ }^{2}$ Department of Preventive Medicine, School of Medicine, Health Promotion Research Center, Kyungpook National University, \\ Daegu, South Korea \\ ${ }^{3}$ Chonnam National University Hwasun Hospital, Jeonnam Regional Cancer Center, Hwasun, Chonnam Province, South Korea \\ ${ }^{4}$ Gwangju-Jeonnam Regional Cardiocerebrovascular Center, Chonnam National University Hospital, Gwangju, South Korea \\ ${ }^{5}$ Department of Food and Nutriton, Sangju Campus, Kyungpook National University, Sangju, Kyungpook Province, South Korea
}

(Received 20 October 2009 - Revised 30 March 2010 - Accepted 13 April 2010 - First published online 21 May 2010)

\begin{abstract}
The relationship between dietary $\mathrm{Zn}$ intake and the risk of atherosclerosis remains unclear, and no epidemiological studies have been reported on the effects of dietary $\mathrm{Zn}$ intake on morphological changes in the vascular wall. We examined the relationship between dietary $\mathrm{Zn}$ intake and common carotid intima-media thickness (IMT) as a marker of subclinical atherosclerosis among the middle-aged and elderly populations. A cross-sectional analysis of a prospective cohort baseline study was performed with 4564 adults aged 40-89 years and free of clinical CVD. Dietary data were collected by trained interviewers using an FFQ. Common carotid IMT was measured using a B-mode ultrasound imaging technique. Subclinical atherosclerosis was determined using carotid IMT, and defined as $>80$ th percentile of carotid IMT or $\geq 1 \mathrm{~mm}$ of carotid IMT. After adjustment for potential confounders, the mean carotid IMT in the low Zn intake group was higher than that in the high Zn intake group. When subclinical atherosclerosis was defined as $>80$ th percentile value of IMT or $\geq 1 \mathrm{~mm}$ of carotid IMT, after adjustment for potential confounders, $\mathrm{Zn}$ intake was inversely related to subclinical atherosclerosis (5th $v$. 1st quintile, OR 0.64, 95\% CI 0.45, 0.90, $P$ for trend=0.069; 5th $v$. 1st quintile, OR $0 \cdot 34,95 \%$ CI $0 \cdot 16,0 \cdot 70, P$ for trend $=0 \cdot 005$, respectively). In persons free of clinical CVD, dietary Zn intake was inversely correlated with subclinical atherosclerosis. The present findings suggest a putative protective role of dietary $\mathrm{Zn}$ intake against the development of atherosclerosis.
\end{abstract}

Zinc: Carotid intima-media thickness: Subclinical atherosclerosis

Atherosclerosis is an arterial disease that induces lumen narrowing and obstruction, and is the most common cause of heart attacks and strokes worldwide. Several lifestyle and nutritional factors have been identified to influence the formation of atherosclerotic plaque ${ }^{(1-4)}$, but the relationship between $\mathrm{Zn}$ intake and atherosclerosis has been inconclusive, although $\mathrm{Zn}$ has been regarded as an antioxidant ${ }^{(5)}$. The protective effects of $\mathrm{Zn}$ on the process of atherosclerosis have been suggested through in vitro and in vivo studies ${ }^{(6-9)}$. $\mathrm{Zn}$ has been shown to inhibit LDL oxidation by macrophages and endothelial cells in vitro ${ }^{(6)}$ and to prevent lesion development in hypercholesterolaemic animals ${ }^{(7)}$. Zn has also been shown to inhibit apoptosis of endothelial cells by inhibiting the activity of caspases ${ }^{(8,9)}$. Nevertheless, limited epidemiological studies have been done on the relationship between $\mathrm{Zn}$ intake and CVD, and the associations of $\mathrm{Zn}$ intake with CVD were not consistent ${ }^{(10-15)}$. A cross-sectional survey showed an inverse relationship between dietary $\mathrm{Zn}$ intake and the prevalence of coronary artery disease ${ }^{(10)}$, and a cohort study reported that dietary $\mathrm{Zn}$ intake showed an inverse association with CVD mortality ${ }^{(11)}$. Two case-control studies reported that CVD patients had higher Zn intakes and lower serum $\mathrm{Zn}$ than the controls ${ }^{(12,13)}$. However, other case-control studies demonstrated that serum $\mathrm{Zn}$ in individuals with atherosclerosis obliterans was higher than that in the healthy control groups ${ }^{(14,15)}$. Therefore, the effects of dietary $\mathrm{Zn}$ on atherosclerosis remain uncertain.

Intima-media thickness (IMT) of large artery walls is a noninvasive marker of early arterial wall alteration. Carotid IMT measurements assessed by B-mode ultrasound have been used as surrogate markers for atherosclerosis in observational studies and clinical research ${ }^{(16)}$. Increase in carotid IMT was directly associated with an increased risk of CHD including myocardial infarction and stroke in cohort studies $^{(17,18)}$.

Abbreviation: IMT, intima-media thickness.

* Corresponding author: M. K. Kim, fax +82 22293 0660, email kmkkim@ hanyang.ac.kr 
To date, no epidemiological studies have been reported on the effect of dietary $\mathrm{Zn}$ intake on morphological changes in the vascular wall. Thus, we examined the relationship between dietary $\mathrm{Zn}$ intake and subclinical atherosclerosis as measured using carotid IMT among the middle-aged and elderly populations.

\section{Subjects and methods}

\section{Study population}

The Korean Multi-Rural Communities Cohort Study in Rural Communities is part of the Korean Genome Epidemiology Study. The Korean Multi-Rural Communities Cohort Study in Rural Communities was initiated in 2004 to construct a genomic cohort and identify risk factors for CVD. As baseline, 7818 subjects aged $\geq 40$ years were recruited from the centres located in Yangpyeong, Namwon and Goryeong between January 2005 and November 2007. Yangpyeong is located $45 \mathrm{~km}$ east of Seoul, the capital of South Korea, and Namwon and Goryeong are located in southwestern and southeastern areas of South Korea, respectively. The majority of the subjects were farmers and housewives. Among 7818 subjects, we excluded subjects who had hypertension ( $n$ 2131), hyperlipidaemia ( $n$ 348), diabetes ( $n$ 734), heart disease $(n$ 502), cerebrovascular disease $(n 273)$ or cancer $(n 173)$ at the baseline survey, and those who reported implausible dietary intake $(<2091$ or $>16726 \mathrm{~kJ} / \mathrm{d}$ or $1000 \mathrm{~g}$ of alcohol/d or more than ten missing food items) ( $n$ 67), and those who reported that they had changed their usual diet during the previous year ( $n$ 277). A total of 4564 subjects aged 40-89 years were included in the final data analysis. The present study was conducted according to the guidelines laid down in the Declaration of Helsinki, and all procedures involving human subjects were approved by the Institutional Review Boards of Hanyang University, Chonnam National University and Keimyung University. Written informed consent was obtained from all subjects.

\section{General characteristics, anthropometrics and biochemical variables}

To overcome the limitations of the multicentre studies, we developed standardised protocols for a questionnaire and each examination procedure including measurements of height and weight and blood pressure and blood sampling. All interviewers and examiners were trained by the same personnel at the coordinating centre.

A structured questionnaire, including information on demographics, education, smoking, alcohol intake, exercise, medical history and female reproductive history, was administered by trained interviewers. Height was measured using a standard height scale to the nearest $0.1 \mathrm{~cm}$, and weight was measured using a metric weight scale to the nearest $0.01 \mathrm{~kg}$ in light clothing without shoes. BMI was calculated as weight $(\mathrm{kg}) /$ height $\left(\mathrm{m}^{2}\right)$. Waist circumference was measured half way between the lowest rib margin and the iliac crest. Blood pressure was measured from the right arm by auscultation using a standard sphygmomanometer and a standard cuff. Two consecutive measurements of blood pressure were done after each subject had been sitting for at least $5 \mathrm{~min}$.
Systolic blood pressure and diastolic blood pressure were recorded to the nearest $2 \mathrm{mmHg}$. If two systolic or diastolic blood pressures were more than $5 \mathrm{mmHg}$ apart, an additional measurement was done, and the mean value of the closest two measurements was used for the subsequent analyses. Blood samples were collected in the morning after at least $8 \mathrm{~h}$ of fasting, and all biochemical markers were analysed on the same day. Plasma total cholesterol, TAG, glucose and HDL-cholesterol were measured using the ADVIA1650 Automatic Analyser (Siemens, New York, NY, USA). If plasma TAG were $<4000 \mathrm{mg} / \mathrm{l}$, LDL-cholesterol was calculated as described by Friedewald et al. ${ }^{(19)}$.

\section{Dietary assessment}

Dietary data were collected by trained interviewers using a food-based FFQ in which each participant was asked to identify the usual frequency of consumption of 106 food items during the previous year and the average serving size consumed. The FFQ consisted of nine frequency categories ranging from 'never or rare' to ' 3 times/d', and three serving sizes were specified. For food items with different seasonal availability, the participants were asked to mark how long they had eaten among four categories: 3, 6, 9 and 12 months. The validity and reproducibility of the FFQ have been reported in detail elsewhere ${ }^{(20)}$. Briefly, the estimated nutrient intakes from the FFQ were compared with those from $12 \mathrm{~d}$ food records during the four seasons. Pearson's correlation coefficient for $\mathrm{Zn}$ was $\mathbf{0} \cdot 33$. Based on the crossclassification analysis, with respect to $\mathrm{Zn}$ intake, $71.8 \%$ of the subjects were classified into the same or adjacent quartiles, and $6.5 \%$ of the subjects were classified into opposite quartiles. Nutrient intake was calculated using a weighted frequency per day and a portion size per unit in each food item. The seventh edition of the Food Composition Table of Korea was used as the nutrient database ${ }^{(21)}$. The major contributing food sources of $\mathrm{Zn}$ were cereal grains $(56 \%)$ followed by oysters (3\%) and milk (3\%) (data not shown). Nevertheless, oyster ingestion explained $54 \%$ of the total variation in dietary $\mathrm{Zn}$ intake, which is attributed to the high $\mathrm{Zn}$ content of oysters and large variation in oyster consumption among the subjects.

\section{Measurement of intima-media thickness}

IMT of common carotid artery was evaluated with the subject in the supine position using high-resolution B-mode ultrasound (SonoAce-9900; Medison Company Limited, Seoul, South Korea) equipped with a $7.5 \mathrm{MHz}$ linear-array transducer. From the longitudinal view of the carotid bifurcation at a point $10 \mathrm{~mm}$ proximal to the common carotid artery, the maximal value of the IMT in a region free of plaque was measured in both carotid arteries. End-diastolic images were captured and saved as files for offline analysis by five sonographers at the three centres. A single trained reader at the reading centre in the Department of Preventive Medicine at Chonnam National University analysed the still images using the Sigma Scan Pro 5.0 (SPSS Inc., Chicago, IL, USA). Between- and within-sonographer reliabilities were evaluated using 180 cases and thirty cases, respectively, and within-reader reliability was tested using thirty-six cases. 
CV between and within sonographers (9.4-9.8 and 4.7-4.9\%, respectively), intraclass correlation coefficients between and within sonographers $(r 0.85-0.88$ and $r$ 0.90-0.91, respectively), a CV within readers $(3 \cdot 8-4.1 \%)$ and a intraclass correlation coefficients within readers ( $r$ 0.92-0.94) all indicated that the IMT measures taken from the three centres by five sonographers and one reader yielded highly reproducible values of common carotid IMT.

\section{Statistical analysis}

Nutrient intakes were adjusted for total energy intake by the residual method. Subjects were categorised into quintiles by dietary $\mathrm{Zn}$ intake. Stratification analysis was performed according to age of the subjects. The subjects aged $<65$ years were considered 'the middle-aged', and the subjects aged $\geq 65$ years were considered 'the elderly'. The general linear model and the Cochran-Mantel-Haenszel analysis with adjustment for age and sex were used to determine differences in means or distribution and the linear trends across the $\mathrm{Zn}$ intake groups. The trend tests were conducted by treating the median value of each group as continuous variable in a multivariate model. The common carotid IMT was calculated as the mean IMT measurement of both carotid arteries. The differences in the means of IMT between $\mathrm{Zn}$ intake groups were assessed using general linear model. When statistically significant effects were demonstrated, Tukey's post hoc comparison test was used to identify group differences at $P<0 \cdot 05$. The normal values of carotid IMT have been established based on the distribution of IMT values in a general healthy population ${ }^{(22,23)}$, so that normal values are different depending on the methodology used for the measurement, age and sex. Subclinical atherosclerosis was defined by the value $>80$ th upper percentile of common carotid IMT $(0.8232 \mathrm{~mm})$ similar to the study done by He et al. ${ }^{(4)}$. However, since IMT tends to increase with age, this upper normal limit $(0.8232 \mathrm{~mm})$ can be too strict for elderly subjects. When this limit was applied to elderly subjects, $36 \%$ of the elderly subjects aged $\geq 65$ years were categorised as having subclinical atherosclerosis. Therefore, another criterion (IMT $=1 \mathrm{~mm}$ ) was also applied to determine the risk of subclinical atherosclerosis. A value of IMT $\geq 1 \mathrm{~mm}$ at any age is related to the significant increase in myocardial infarction and/or cerebrovascular disease ${ }^{(24)}$. Non-conditional logistic regression analysis was applied to obtain the OR and corresponding $95 \%$ CI for subclinical atherosclerosis. Potential confounders were identified by examining the distributions of characteristics that can affect atherosclerosis by $\mathrm{Zn}$ intake groups. The variables that showed significantly different distributions among $\mathrm{Zn}$ intake groups or showed significant linear trends across $\mathrm{Zn}$ intake groups were considered as potential confounders and adjusted in the analyses. Three different models were applied to examine the associations of $\mathrm{Zn}$ intake with IMT. Age and sex were adjusted as confounders in the first model, and education, alcohol intake (g/d), smoking status (current, former or non-smoker), regular exercise (yes/no), waist circumference and serum HDLcholesterol were further adjusted in the second model. The final model additionally adjusted dietary factors such as quintiles of total energy, protein, fat, carbohydrate, $\beta$-carotene, vitamins $\mathrm{C}$ and $\mathrm{E}$, folate, dietary fibre and cholesterol intakes.
All statistical analyses were performed using the SAS software (version 9.1; SAS Institute, Inc., Cary, NC, USA), and $P$ values $<0.05$ were considered significant.

\section{Results}

The present study subjects consisted of Koreans aged 40-89 years sampled in three rural areas. General characteristics of the subjects are given in Table 1 . Men made up $40.2 \%$ of the total number of subjects. The mean ages of men and women were 61.3 and 59.7 years, respectively. The proportion of the subjects aged $\geq 65$ years was $38.5 \%$ of the total number

Table 1. General characteristics of the study subjects

(Mean values and standard deviations or frequency)

\begin{tabular}{|c|c|c|c|c|}
\hline \multirow[b]{2}{*}{ Characteristics } & \multicolumn{2}{|c|}{ Men $(n$ 1837) } & \multicolumn{2}{|c|}{ Women (n 2727) } \\
\hline & Mean & SD & Mean & SD \\
\hline Age (years) & $61 \cdot 3$ & 9.9 & $59 \cdot 7$ & $10 \cdot 1$ \\
\hline Height $(\mathrm{cm})$ & $165 \cdot 0$ & $6 \cdot 2$ & $152 \cdot 5$ & $6 \cdot 0$ \\
\hline Weight (kg) & 64.4 & $10 \cdot 1$ & $56 \cdot 1$ & $8 \cdot 8$ \\
\hline BMI $\left(\mathrm{kg} / \mathrm{m}^{2}\right)$ & $23 \cdot 6$ & $3 \cdot 0$ & $24 \cdot 1$ & $3 \cdot 2$ \\
\hline Waist circumference $(\mathrm{cm})$ & 84.5 & $8 \cdot 3$ & $82 \cdot 4$ & $9 \cdot 0$ \\
\hline \multicolumn{5}{|l|}{ Seated blood pressure $(\mathrm{mmHg})$} \\
\hline Systolic & $124 \cdot 2$ & $16 \cdot 5$ & $121 \cdot 0$ & $17 \cdot 6$ \\
\hline Diastolic & $79 \cdot 8$ & $10 \cdot 2$ & 77.6 & $10 \cdot 1$ \\
\hline Total cholesterol (mg/l) & 1900 & 352 & 2021 & 355 \\
\hline LDL-cholesterol (mg/l) & 1165 & 315 & 1299 & 316 \\
\hline HDL-cholesterol (mg/l) & 443 & 117 & 458 & 104 \\
\hline $\mathrm{TAG}(\mathrm{mg} / \mathrm{l})$ & 1544 & 1138 & 1346 & 781 \\
\hline Fasting blood glucose (mg/l) & 980 & 168 & 940 & 140 \\
\hline Alcohol intake $(\mathrm{g} / \mathrm{d})$ & $25 \cdot 9$ & $59 \cdot 0$ & $3 \cdot 2$ & $27 \cdot 1$ \\
\hline \multicolumn{5}{|l|}{ Dietary intake* } \\
\hline Energy (kJ/d) & $7261 \cdot 8$ & $2113 \cdot 8$ & $6370 \cdot 7$ & $1840 \cdot 3$ \\
\hline Protein $(\mathrm{g} / \mathrm{d})$ & $46 \cdot 4$ & 8.6 & $45 \cdot 2$ & 8.5 \\
\hline Fat $(g / d)$ & $19 \cdot 2$ & $7 \cdot 8$ & $16 \cdot 7$ & $8 \cdot 0$ \\
\hline Carbohydrate (g/d) & $287 \cdot 6$ & 30.7 & 295.5 & $30 \cdot 1$ \\
\hline$\beta$-Carotene $(\mu \mathrm{g} / \mathrm{d})$ & $1766 \cdot 0$ & $1282 \cdot 7$ & $1785 \cdot 1$ & 1394.5 \\
\hline Vitamin C (mg/d) & $75 \cdot 1$ & 39.9 & $89 \cdot 3$ & $51 \cdot 1$ \\
\hline Folate $(\mu \mathrm{g} / \mathrm{d})$ & $159 \cdot 6$ & $67 \cdot 2$ & $170 \cdot 4$ & $75 \cdot 4$ \\
\hline Vitamin E (mg/d) & $5 \cdot 8$ & 1.9 & $6 \cdot 0$ & $2 \cdot 3$ \\
\hline Fibre $(g / d)$ & $4 \cdot 7$ & $1 \cdot 8$ & 4.9 & 1.9 \\
\hline Cholesterol (mg/d) & $107 \cdot 3$ & 89.9 & 101.4 & 87.5 \\
\hline $\mathrm{Zn}(\mathrm{mg} / \mathrm{d})$ & $6 \cdot 1$ & $1 \cdot 7$ & $6 \cdot 0$ & $1 \cdot 2$ \\
\hline \multicolumn{5}{|l|}{ Frequency ( $n$ and \%) } \\
\hline Menopausal women & & & 2137 & $78 \cdot 4$ \\
\hline \multicolumn{5}{|l|}{ Education } \\
\hline Less than elementary & 285 & $15 \cdot 6$ & 1106 & $40 \cdot 7$ \\
\hline Elementary & 686 & 37.5 & 901 & $33 \cdot 1$ \\
\hline Middle school & 365 & $20 \cdot 0$ & 322 & $11 \cdot 8$ \\
\hline High school & 338 & 18.5 & 311 & 11.4 \\
\hline College or higher & 155 & $8 \cdot 4$ & 82 & $3 \cdot 0$ \\
\hline \multicolumn{5}{|l|}{ Smoking status } \\
\hline Non-smoker & 428 & $23 \cdot 3$ & 2579 & $94 \cdot 6$ \\
\hline Former smoker & 696 & 37.9 & 49 & $1 \cdot 8$ \\
\hline Current smoker & 712 & $38 \cdot 8$ & 97 & $3 \cdot 6$ \\
\hline \multicolumn{5}{|l|}{ Alcohol intake } \\
\hline Non-drinker & 430 & $23 \cdot 5$ & 1757 & 64.5 \\
\hline Former drinker & 180 & $9 \cdot 8$ & 66 & $2 \cdot 4$ \\
\hline Current drinker & 1224 & $66 \cdot 7$ & 901 & $33 \cdot 1$ \\
\hline \multicolumn{5}{|l|}{ Regular exercise } \\
\hline No & 1387 & $75 \cdot 5$ & 2028 & 74.4 \\
\hline Yes & 450 & 24.5 & 698 & $25 \cdot 6$ \\
\hline
\end{tabular}

* All nutrients were total energy adjusted by residual method after log transformation.

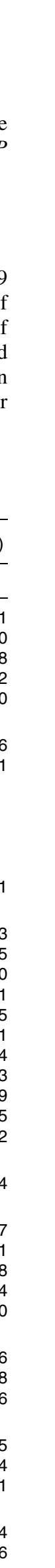


of subjects. The proportions of the subjects whose BMI was $>25 \mathrm{~kg} / \mathrm{m}^{2}$ were $31.9 \%$ of the men and $36.1 \%$ of the women, respectively. The proportion of postmenopausal women was $78.4 \%$. Men were more likely to have a higher education, and to be current smokers and current drinkers than women. Means of total daily energy intakes were $7261.8 \mathrm{~kJ}(1736.6 \mathrm{kcal})$ for men and $6370.7 \mathrm{~kJ}(1523.5 \mathrm{kcal})$ for women. Means of daily $\mathrm{Zn}$ intake for men and women were 6.1 and $6.0 \mathrm{mg} / \mathrm{d}$ after adjustment for total energy intake by the residual method.

To determine the potential confounding factors, the distributions of selected characteristics were examined across five $\mathrm{Zn}$ intake groups, which are given in Table 2 . The median $\mathrm{Zn}$ intakes of the first, second, third, fourth and fifth quintiles were $5 \cdot 00,5.48,5.85,6.29$ and $7 \cdot 19 \mathrm{mg} / \mathrm{d}$, respectively. Age, total energy intake, carbohydrate and proportion of current smokers decreased across the $\mathrm{Zn}$ intake groups. The proportions of higher education, current drinkers, regular exercise, waist circumference, serum HDL-cholesterol, and intakes of alcohol, protein, fat, $\beta$-carotene, vitamin $\mathrm{C}$, folate, vitamin $\mathrm{E}$, fibre and cholesterol increased across $\mathrm{Zn}$ intake groups. Differences in the proportion of males were significant. All variables for which significant linear trends or significant differences in means were used as covariates are given in Tables 3 and 4 .

Adjusted IMT means by $\mathrm{Zn}$ intake group are given in Table 3 . The middle-aged ( $<65$ years) and the elderly $(\geq 65$ years) populations showed similar median $\mathrm{Zn}$ intakes. Means of IMT in the elderly population were higher than those in the middle-aged population. After adjustment for age, sex, education, alcohol intake, smoking, regular exercise, waist circumference, HDL-cholesterol and dietary factors (quintiles of total energy, protein, fat, carbohydrate, $\beta$-carotene, vitamins $\mathrm{C}$ and $\mathrm{E}$, folate, dietary fibre and cholesterol intakes), adjusted IMT mean in the first quintile of $\mathrm{Zn}$ intake group was significantly higher than that in the fifth quintile group among the total subjects. In the middle-aged population, the first quintile group showed higher adjusted IMT means than the fifth quintile group in the first and second models. With respect to the elderly population, after adjusting for potential confounders, adjusted IMT mean in the first quintile group was higher than that in the fifth quintile group, but the difference was NS. The interaction between quintile of $\mathrm{Zn}$ intake and age group was not statistically significant (data not shown). Adjusted IMT means by Zn intake from seafood and grain showed the same direction with the relationship between total dietary $\mathrm{Zn}$ and IMT (data not shown).

The relationships between $\mathrm{Zn}$ intake and the risk of subclinical atherosclerosis are given in Table 4 . When subclinical atherosclerosis was defined by $>80$ th percentile value of IMT $(0.8232 \mathrm{~mm}), 10.4 \%$ of the middle-aged population and $35.7 \%$ of the elderly population were classified as having subclinical atherosclerosis. After adjustment for potential confounders in the third model, $\mathrm{Zn}$ intake was inversely related to subclinical atherosclerosis (5th $v$. 1st quintile, OR $0.64,95 \%$ CI $0.45,0.90, P$ for trend=0.069). In the middleaged population, a significant inverse correlation between $\mathrm{Zn}$ intake and subclinical atherosclerosis was found in the third model (5th $v$. 1st quintile, OR $0.44,95 \%$ CI $0 \cdot 26$, $0.76, P$ for trend=0.048). However, no significant relation was found in the elderly population.
When subclinical atherosclerosis was defined by $\geq 1 \mathrm{~mm}$ of IMT, $1.6 \%$ of the middle-aged population and $7.9 \%$ of the elderly population were classified as having subclinical atherosclerosis. Zn intake was inversely correlated with the risk of subclinical atherosclerosis after adjusting for potential confounders (5th $v$. 1st quintile, OR $0 \cdot 34,95 \%$ CI $0 \cdot 16,0 \cdot 70$, $P$ for trend=0.005). The elderly subjects showed an inverse relationship between $\mathrm{Zn}$ intake and the risk of subclinical atherosclerosis (5th v. 1st quintile, OR $0 \cdot 33$, $95 \%$ CI $0 \cdot 14$, $0.77, P$ for trend=0.013). No significant correlations were found in middle-aged adult subjects.

When the subjects who were diagnosed as having hypertension, hyperlipidaemia, diabetes, heart disease, cerebrovascular disease or cancer were included and diagnosed diseases were adjusted in the model, similar trends were found between $\mathrm{Zn}$ intake and the risk of carotid atherosclerosis (results not shown).

\section{Discussion}

Carotid IMT is known as a surrogate marker for carotid atherosclerosis. In the present cross-sectional study, the low $\mathrm{Zn}$ intake group displayed a higher mean IMT than the high $\mathrm{Zn}$ intake group. An inverse relationship between dietary $\mathrm{Zn}$ intake and common carotid atherosclerosis was demonstrated in the middle-aged and elderly populations. The present findings suggest that adequate $\mathrm{Zn}$ intake may have a beneficial effect on the risk of atherosclerosis among the middle-aged and elderly populations.

In the present study, daily $\mathrm{Zn}$ intake was estimated using the FFQ. However, it is inappropriate to compare the absolute dietary $\mathrm{Zn}$ intake estimated using the FFQ to the estimated average requirements or dietary $\mathrm{Zn}$ intakes estimated by other dietary assessment methods. Therefore, we conducted $3 \mathrm{~d} 24 \mathrm{~h}$ recalls in a subgroup of the subjects ( $n$ 880) (data not shown). The mean energy intakes for men and women in the subgroup were 7439 (SD 2273) kJ and 5890 (SD $1750) \mathrm{kJ}$, which were similar to the energy intakes estimated by the FFQ. The means of daily $\mathrm{Zn}$ intakes for men ( $n$ 350) and women ( $n 530)$ were 8.7 and $7.4 \mathrm{mg} / \mathrm{d}$, which were higher than the Korean estimated average requirements for $\mathrm{Zn}^{(25)}$, but lower than $\mathrm{Zn}$ intakes estimated by multiple day $24 \mathrm{~h}$ recalls from a healthy Chinese sample $(8.9-11.9 \mathrm{mg} / \mathrm{d})^{(26)}$, an older European sample $(11.0-11.3 \mathrm{mg} / \mathrm{d})$ and an adult sample from the United States $(9 \cdot 7-14 \cdot 2 \mathrm{mg} / \mathrm{d})^{(27-29)}$.

Carotid IMT has been used as an intermediate or proxy end point for CVD. Carotid IMT has been consistently associated with the incidence of CHD in cohort studies ${ }^{(17,18,30)}$. The association between carotid IMT and diet, such as consumption of fruit, olive oil, fat, alcohol, fish and isoflavone, has been determined ${ }^{(1-4,31)}$, but the relationship between carotid IMT and $\mathrm{Zn}$ intake has not been investigated.

In the present study, the risk of subclinical atherosclerosis in the high $\mathrm{Zn}$ intake group was significantly lower than that in the low $\mathrm{Zn}$ intake group. In particular, when 80th upper percentile values of common carotid IMT were used to determine the OR, after adjusting for potential confounders, the risks of subclinical atherosclerosis in the fifth quintile group were lower than those in the first quintile group among the middle-aged populations (5th $v$. 1st quintile, OR $0.44,95 \%$ CI $0.26,0.76, P$ for trend=0.048). The elderly population 
Table 2. Age- and sex-adjusted characteristics of the study population by zinc intake group

(Mean values with their standard errors)

\begin{tabular}{|c|c|c|c|c|c|c|c|c|c|c|c|c|}
\hline \multirow[b]{3}{*}{ Characteristics } & \multicolumn{10}{|c|}{ Zn intake } & \multirow[b]{3}{*}{$P$ for difference } & \multirow[b]{3}{*}{$P$ for linear trend } \\
\hline & \multicolumn{2}{|c|}{ Q1 } & \multicolumn{2}{|c|}{ Q2 } & \multicolumn{2}{|c|}{ Q3 } & \multicolumn{2}{|c|}{ Q4 } & \multicolumn{2}{|c|}{ Q5 } & & \\
\hline & Mean & SE & Mean & SE & Mean & SE & Mean & SE & Mean & SE & & \\
\hline$n$ & \multicolumn{2}{|c|}{912} & \multicolumn{2}{|c|}{913} & \multicolumn{2}{|c|}{912} & \multicolumn{2}{|c|}{913} & \multicolumn{2}{|c|}{914} & & \\
\hline Median $\mathrm{Zn}$ intake $(\mathrm{mg} / \mathrm{d})$ & \multicolumn{2}{|c|}{5.00} & \multicolumn{2}{|c|}{5.48} & \multirow{2}{*}{\multicolumn{2}{|c|}{$\begin{array}{c}5 \cdot 85 \\
5 \cdot 65-6 \cdot 04\end{array}$}} & \multirow{2}{*}{\multicolumn{2}{|c|}{$\begin{array}{c}6 \cdot 29 \\
6.04-6 \cdot 63\end{array}$}} & \multicolumn{2}{|c|}{$7 \cdot 19$} & & \\
\hline Range of $Z n$ intake & \multicolumn{2}{|c|}{$2 \cdot 81-5 \cdot 27$} & \multicolumn{2}{|c|}{$5 \cdot 27-5 \cdot 65$} & & & & & \multicolumn{2}{|c|}{$6 \cdot 63-40 \cdot 38$} & & \\
\hline Age (years) & $62 \cdot 4$ & $0.3 \dagger$ & $61 \cdot 8$ & 0.3 & $60 \cdot 4$ & 0.3 & $59 \cdot 4$ & 0.3 & $57 \cdot 6$ & 0.3 & $<0.0001$ & $<0.0001$ \\
\hline $\mathrm{BMI}\left(\mathrm{kg} / \mathrm{m}^{2}\right)$ & $23 \cdot 7$ & 0.1 & $23 \cdot 9$ & $0 \cdot 1$ & 23.9 & 0.1 & 23.9 & 0.1 & $23 \cdot 9$ & $0 \cdot 1$ & 0.573 & 0.299 \\
\hline Waist circumference $(\mathrm{cm})$ & 82.5 & 0.3 & $83 \cdot 0$ & 0.3 & 83.7 & 0.3 & 83.5 & 0.3 & 83.5 & 0.3 & 0.033 & 0.015 \\
\hline \multicolumn{13}{|l|}{ Blood pressure $(\mathrm{mmHg})$} \\
\hline Systolic & $122 \cdot 2$ & 0.6 & $121 \cdot 7$ & 0.6 & $122 \cdot 4$ & 0.6 & $123 \cdot 0$ & 0.6 & $122 \cdot 1$ & 0.6 & 0.568 & 0.751 \\
\hline Diastolic & $78 \cdot 2$ & 0.3 & $78 \cdot 3$ & 0.3 & $78 \cdot 1$ & 0.3 & 78.8 & 0.3 & 78.9 & 0.3 & 0.386 & 0.078 \\
\hline Total cholesterol (mg/l) & 1980 & 12 & 1983 & 12 & 1964 & 12 & 1965 & 12 & 1971 & 12 & 0.713 & 0.424 \\
\hline LDL-cholesterol (mg/l) & 1259 & 11 & 1253 & 11 & 1242 & 11 & 1236 & 11 & 1240 & 11 & 0.527 & 0.153 \\
\hline HDL-cholesterol (mg/l) & 445 & 4 & 447 & 4 & 444 & 4 & 458 & 4 & 464 & 4 & 0.0001 & $<0.0001$ \\
\hline TAG $(\mathrm{mg} / \mathrm{l})$ & 1412 & 31 & 1494 & 31 & 1418 & 31 & 1417 & 31 & 1388 & 31 & $0 \cdot 164$ & 0.192 \\
\hline Fasting blood glucose (mg/l) & 956 & 5 & 962 & 5 & 951 & 5 & 952 & 5 & 960 & 5 & 0.446 & 0.909 \\
\hline Alcohol intake $(\mathrm{g})$ & 8.8 & 1.4 & $12 \cdot 6$ & 1.4 & 11.8 & 1.4 & $14 \cdot 1$ & 1.4 & 14.4 & 1.4 & 0.046 & 0.008 \\
\hline Dietary intakeł & & & & & & & & & & & & \\
\hline Energy (kJ/d) & $7051 \cdot 0$ & $61 \cdot 9$ & $6663 \cdot 8$ & 61.5 & 6554.5 & 61.5 & $6608 \cdot 1$ & 61.5 & 6785.5 & 61.9 & $<0.0001$ & 0.029 \\
\hline Protein $(g / d)$ & 37.6 & 0.2 & 41.9 & 0.2 & $45 \cdot 6$ & 0.2 & 48.9 & 0.2 & $54 \cdot 3$ & 0.2 & $<0.0001$ & $<0.0001$ \\
\hline Fat $(g / d)$ & $14 \cdot 3$ & $0 \cdot 2$ & 14.9 & 0.2 & $17 \cdot 2$ & 0.2 & $19 \cdot 2$ & 0.2 & $23 \cdot 0$ & 0.2 & $<0.0001$ & $<0.0001$ \\
\hline Carbohydrate (g/d) & 288.5 & 1.0 & 302.5 & 1.0 & 298.4 & 1.0 & 293.4 & 1.0 & 278.9 & 1.0 & $<0.0001$ & $<0.0001$ \\
\hline$\beta$-Carotene $(\mu \mathrm{g} / \mathrm{d})$ & $1228 \cdot 2$ & 41.9 & $1369 \cdot 9$ & $41 \cdot 8$ & $1712 \cdot 6$ & $41 \cdot 7$ & $2013 \cdot 7$ & $41 \cdot 7$ & $2561 \cdot 2$ & $42 \cdot 0$ & $<0.0001$ & $<0.0001$ \\
\hline Vitamin C (mg/d) & $63 \cdot 3$ & 1.4 & 69.9 & 1.4 & 81.4 & 1.4 & $92 \cdot 0$ & 1.4 & $111 \cdot 2$ & 1.4 & $<0.0001$ & $<0.0001$ \\
\hline Folate $(\mu \mathrm{g} / \mathrm{d})$ & $130 \cdot 2$ & $2 \cdot 2$ & 139.9 & $2 \cdot 1$ & $164 \cdot 1$ & $2 \cdot 1$ & $180 \cdot 2$ & $2 \cdot 1$ & $215 \cdot 6$ & $2 \cdot 2$ & $<0.0001$ & $<0.0001$ \\
\hline Vitamin $E(\mathrm{mg} / \mathrm{d})$ & 5.04 & 0.07 & $5 \cdot 19$ & 0.07 & $5 \cdot 74$ & 0.07 & $6 \cdot 24$ & 0.07 & $7 \cdot 32$ & 0.07 & $<0.0001$ & $<0.0001$ \\
\hline Fibre $(g / d)$ & 3.85 & 0.06 & $4 \cdot 32$ & 0.06 & 4.88 & 0.06 & $5 \cdot 24$ & 0.06 & $5 \cdot 81$ & 0.06 & $<0.0001$ & $<0.0001$ \\
\hline Cholesterol (mg/d) & $66 \cdot 7$ & $2 \cdot 8$ & $79 \cdot 8$ & $2 \cdot 8$ & $102 \cdot 2$ & $2 \cdot 8$ & 121.4 & $2 \cdot 8$ & $148 \cdot 9$ & $2 \cdot 8$ & $<0.0001$ & $<0.0001$ \\
\hline Men $(\%)$ & & & & & & & & & & & 0.006 & 0.137 \\
\hline Menopausal women (\%)§ & & & & & & & & & & & 0.900 & 0.928 \\
\hline Higher education (\%)\| & & & & & & & & & & & $<0.0001$ & $<0.0001$ \\
\hline Current smoker (\%) & & & & & & & & & & & $<0.0001$ & 0.001 \\
\hline Current drinker (\%) & & & & & & & & & & & 0.0001 & $<0.0001$ \\
\hline Regular exercise (\%) & & & & & & & & & & & $<0.0001$ & $<0.0001$ \\
\hline
\end{tabular}

Q, quintile.

${ }^{*} P$ values for differences across groups and $P$ values for the trends were determined using general linear model for continuous variables after adjustment for age and sex, and using the Cochran-Mantel-Haenszel test for categorical variables after adjustment for age (men and premenopausal women) or age and sex (higher education, current smoker, current drinker and regular exercise).

$\dagger$ All continuous variables were adjusted for age and sex.

$\ddagger$ All nutrients were total energy adjusted by residual method after log transformation.

$\S$ The proportion among women subjects.

$\| \geq$ High school graduation. 
Table 3. Common carotid intima-media thickness (IMT) by zinc intake group (Mean values and $95 \%$ confidence intervals)

\begin{tabular}{|c|c|c|c|c|c|c|c|c|c|c|c|}
\hline & \multicolumn{10}{|c|}{ Zn intake } & \multirow[b]{3}{*}{$P^{*}$} \\
\hline & \multicolumn{2}{|r|}{ Q1 } & \multicolumn{2}{|c|}{ Q2 } & \multicolumn{2}{|c|}{ Q3 } & \multicolumn{2}{|c|}{ Q4 } & \multicolumn{2}{|c|}{ Q5 } & \\
\hline & Mean & $95 \% \mathrm{Cl}$ & Mean & $95 \% \mathrm{Cl}$ & Mean & $95 \% \mathrm{Cl}$ & Mean & $95 \% \mathrm{Cl}$ & Mean & $95 \% \mathrm{Cl}$ & \\
\hline \multicolumn{12}{|l|}{ Total subjects } \\
\hline$n$ & \multirow{2}{*}{\multicolumn{2}{|c|}{$\begin{array}{c}912 \\
5.00(2.81-5.27)\end{array}$}} & \multicolumn{2}{|c|}{913} & \multicolumn{2}{|c|}{912} & \multicolumn{2}{|c|}{913} & \multicolumn{2}{|c|}{914} & \\
\hline Median $\mathrm{Zn}$ intake (mg) (range) & & & 5.48 & $27-5 \cdot 65)$ & 5.85 & $65-6 \cdot 04)$ & 6.29 & $04-6 \cdot 63)$ & 7.19 & $3-40 \cdot 38)$ & \\
\hline Adjusted IMT mean $1(\mathrm{~mm}) \dagger$ & $0.733^{\mathrm{a}}$ & $0.725,0.741$ & $0.716^{\mathrm{b}}$ & $0.708,0.724$ & $0.715^{\mathrm{b}}$ & $0.707,0.723$ & $0.723^{\mathrm{a}, \mathrm{b}}$ & $0.715,0.731$ & $0.710^{\mathrm{b}}$ & $0.702,0.718$ & $<0.001$ \\
\hline Adjusted IMT mean $2(\mathrm{~mm}) \ddagger$ & $0.731^{\mathrm{a}}$ & $0.722,0.741$ & $0.715^{\mathrm{b}}$ & $0.706,0.725$ & $0.714^{b}$ & $0.705,0.723$ & $0.724^{\mathrm{a}, \mathrm{b}}$ & $0.716,0.733$ & $0.715^{\mathrm{b}}$ & $0.706,0.723$ & 0.007 \\
\hline Adjusted IMT mean $3(\mathrm{~mm}) \S$ & $0.732^{\mathrm{a}}$ & $0.721,0.743$ & $0 \cdot 717^{\mathrm{a}, \mathrm{b}}$ & $0.707,0.727$ & $0 \cdot 713^{b}$ & $0.704,0.722$ & $0.721^{\mathrm{a}, \mathrm{b}}$ & $0.711,0.730$ & $0.707^{b}$ & $0.696,0.717$ & 0.006 \\
\hline \multicolumn{12}{|l|}{ Subjects aged $<65$ years } \\
\hline & \multicolumn{2}{|c|}{477} & \multirow{2}{*}{\multicolumn{2}{|c|}{$\begin{array}{c}503 \\
5.48(5.27-5.65)\end{array}$}} & \multirow{2}{*}{\multicolumn{2}{|c|}{$\begin{array}{c}551 \\
5.85(5.65-6.04)\end{array}$}} & \multirow{2}{*}{\multicolumn{2}{|c|}{615}} & \multicolumn{2}{|c|}{659} & \\
\hline Median $\mathrm{Zn}$ intake (mg) (range) & \multicolumn{2}{|c|}{$5.01(2.81-5.27)$} & & & & & & $6.29(6.04-6.63)$ & \multicolumn{2}{|c|}{$7.18(6.63-24.00)$} & \\
\hline Adjusted IMT mean $1(\mathrm{~mm}) \dagger$ & $0.688^{\mathrm{a}}$ & $0.678,0.698$ & $0.670^{a, b}$ & $0.660,0.680$ & $0.668^{\mathrm{b}}$ & $0.659,0.678$ & $0.678^{a, b}$ & $0.669,0.687$ & $0.668^{\mathrm{b}}$ & $0.660,0.677$ & 0.018 \\
\hline Adjusted IMT mean $2(\mathrm{~mm}) \ddagger$ & $0.686^{\mathrm{a}}$ & $0.674,0.697$ & $0.668^{a, b}$ & $0.657,0.679$ & $0.666^{b}$ & $0.656,0.677$ & $0.677^{\mathrm{a}, \mathrm{b}}$ & $0.667,0.687$ & $0.670^{a, b}$ & $0.660,0.679$ & 0.026 \\
\hline Adjusted IMT mean $3(\mathrm{~mm}) \S$ & $0.687^{\mathrm{a}}$ & $0.673,0.700$ & $0.669^{\mathrm{a}}$ & $0.657,0.680$ & $0.665^{\mathrm{a}}$ & $0.655,0.676$ & $0.675^{a}$ & $0.665,0.686$ & $0.666^{\mathrm{a}}$ & $0.655,0.677$ & 0.038 \\
\hline \multicolumn{12}{|l|}{ Subjects aged $\geq 65$ years } \\
\hline & \multirow{2}{*}{\multicolumn{2}{|c|}{$\begin{array}{c}435 \\
4.98(2.86-5.27)\end{array}$}} & \multirow{2}{*}{\multicolumn{2}{|c|}{$\begin{array}{c}410 \\
5.47(5.27-5.65)\end{array}$}} & \multirow{2}{*}{\multicolumn{2}{|c|}{361}} & \multirow{2}{*}{\multicolumn{2}{|c|}{298}} & \multicolumn{2}{|c|}{255} & \\
\hline Median $\mathrm{Zn}$ intake $(\mathrm{mg})$ (range) & & & & & & $66-6.04)$ & & $05-6 \cdot 62)$ & $7 \cdot 21$ & $63-40 \cdot 4)$ & \\
\hline Adjusted IMT mean $1(\mathrm{~mm}) \dagger$ & $0.805^{\mathrm{a}}$ & $0.792,0.818$ & $0.789^{a, b}$ & $0.776,0.802$ & $0.790^{\mathrm{a}, \mathrm{b}}$ & $0.775,0.804$ & $0.794^{a, b}$ & $0.779,0.810$ & $0.775^{\mathrm{b}}$ & $0.758,0.792$ & 0.084 \\
\hline Adjusted IMT mean $2(\mathrm{~mm}) \ddagger$ & $0.794^{\mathrm{a}}$ & $0.776,0.812$ & $0.782^{\mathrm{a}}$ & $0.763,0.800$ & $0.781^{\mathrm{a}}$ & $0.762,0.800$ & $0.791^{\mathrm{a}}$ & $0.771,0.810$ & $0.775^{\mathrm{a}}$ & $0.756,0.794$ & 0.384 \\
\hline Adjusted IMT mean $3(\mathrm{~mm}) \S$ & $0.795^{a}$ & $0.775,0.816$ & $0.784^{\mathrm{a}}$ & $0.766,0.803$ & $0.778^{\mathrm{a}}$ & $0.759,0.797$ & $0.782^{\mathrm{a}}$ & $0.761,0.803$ & $0.759^{\mathrm{a}}$ & $0.737,0.782$ & 0.150 \\
\hline
\end{tabular}

Q, quintile.

${ }^{a, b}$ Mean values with unlike superscript letters within a row were significantly different among the three groups by Tukey's multiple comparison test. ${ }^{*} P$ values for differences across groups were obtained using the general linear model.

$\dagger$ Adjusted for age and sex.

$\ddagger$ Adjusted for age, sex, education, alcohol intake, smoking, regular exercise, waist circumference and HDL-cholesterol.

$\S$ Adjusted for age, sex, education, alcohol intake, smoking, regular exercise, waist circumference, HDL-cholesterol and dietary factors (quintiles of total energy, protein, fat, carbohydrate, $\beta$-carotene, vitamins $\mathrm{C}$ and $\mathrm{E}$, folate, dietary fibre and cholesterol). 


\begin{tabular}{|c|c|c|c|c|c|c|c|c|c|c|}
\hline & \multicolumn{9}{|c|}{ Zn intake } & \multirow[b]{3}{*}{$P$ for linear trend } \\
\hline & \multirow{2}{*}{$\frac{\text { Q1 }}{\text { OR }}$} & \multicolumn{2}{|c|}{ Q2 } & \multicolumn{2}{|c|}{ Q3 } & \multicolumn{2}{|c|}{ Q4 } & \multicolumn{2}{|c|}{ Q5 } & \\
\hline & & OR & $95 \% \mathrm{Cl}$ & OR & $95 \% \mathrm{Cl}$ & OR & $95 \% \mathrm{Cl}$ & OR & $95 \% \mathrm{Cl}$ & \\
\hline \multicolumn{11}{|l|}{ Criterion: IMT> 80th percentile $(0.8232 \mathrm{~mm})$} \\
\hline & 912 & \multicolumn{2}{|c|}{913} & \multicolumn{2}{|c|}{912} & \multicolumn{2}{|c|}{913} & \multicolumn{2}{|c|}{914} & \\
\hline Median Zn intake (mg) (range) & $5.00(2 \cdot 81-5 \cdot 27)$ & \multicolumn{2}{|c|}{$5 \cdot 48(5 \cdot 27-5 \cdot 65)$} & \multicolumn{2}{|c|}{$5 \cdot 85(5 \cdot 65-6 \cdot 04)$} & \multicolumn{2}{|c|}{$6 \cdot 29(6 \cdot 04-6 \cdot 63)$} & \multicolumn{2}{|c|}{$7 \cdot 19(6 \cdot 63-40 \cdot 38)$} & \\
\hline Subjects with IMT > 80th percentiles (\%) & $235(25 \cdot 8)$ & \multicolumn{2}{|c|}{$177(19.4)$} & \multicolumn{2}{|c|}{$170(18.6)$} & \multicolumn{2}{|c|}{$190(20.8)$} & \multicolumn{2}{|c|}{$148(16 \cdot 2)$} & \\
\hline Multivariate-adjusted OR $1^{*}$ & 1.00 & 0.71 & $0.56-0.91$ & 0.78 & $0.62-0.10$ & 1.00 & $0 \cdot 79-1.27$ & 0.80 & $0.62-1.03$ & 0.532 \\
\hline Multivariate-adjusted OR $2 \dagger$ & 1.00 & 0.74 & $0.58-0.94$ & 0.78 & $0.61-0.99$ & 1.03 & $0.81-1.32$ & 0.83 & $0.64-1.09$ & 0.768 \\
\hline Multivariate-adjusted OR 3‡ & 1.00 & 0.72 & $0.55-0.93$ & 0.70 & $0.52-0.93$ & 0.86 & $0.63-1.17$ & 0.64 & $0.45-0.90$ & 0.069 \\
\hline \multicolumn{11}{|l|}{ Subjects aged $<65$ years } \\
\hline$n$ & 477 & \multirow{2}{*}{\multicolumn{2}{|c|}{$\begin{array}{c}503 \\
5.48(5.27-5.65)\end{array}$}} & \multicolumn{2}{|c|}{$\begin{array}{c}551 \\
5.85(5.65-6.04)\end{array}$} & & 15 & & 59 & \\
\hline Median $\mathrm{Zn}$ intake (mg) (range) & $5 \cdot 01(2 \cdot 81-5 \cdot 27)$ & & & $5 \cdot 85$ & $65-6 \cdot 04)$ & $6 \cdot 25$ & $04-6 \cdot 63)$ & $7 \cdot 18$ & $3-24 \cdot 00)$ & \\
\hline Subjects with IMT > 80th percentiles (\%) & $69(14.5)$ & & (8.9) & & $(8 \cdot 3)$ & & 12.0) & & $(8 \cdot 8)$ & \\
\hline Multivariate-adjusted OR $1^{*}$ & 1.00 & 0.57 & $0.38-0.87$ & 0.61 & $0.40-0.91$ & 0.84 & $0.59-1 \cdot 22$ & 0.68 & $0.47-1.00$ & 0.365 \\
\hline Multivariate-adjusted OR $2 \dagger$ & 1.00 & 0.56 & $0.37-0.85$ & 0.58 & $0.39-0.88$ & 0.82 & $0.56-1.19$ & 0.67 & $0.45-1.00$ & 0.364 \\
\hline Multivariate-adjusted OR 3‡ & 1.00 & 0.49 & $0.32-0.77$ & 0.46 & $0.28-0.75$ & 0.59 & $0.36-0.96$ & 0.44 & $0.26-0.76$ & 0.048 \\
\hline Subjects aged $\geq 65$ years & & & & & & & & & & \\
\hline$n$ & 435 & & 10 & & 361 & & 98 & & 55 & \\
\hline Median $\mathrm{Zn}$ intake (mg) (range) & $4.98(2 \cdot 86-5 \cdot 27)$ & $5 \cdot 47$ & $27-5 \cdot 65)$ & $5 \cdot 85$ & $66-6 \cdot 04)$ & $6 \cdot 3$ & $05-6 \cdot 62)$ & $7 \cdot 21$ & $53-40 \cdot 4)$ & \\
\hline Subjects with IMT > 80th percentiles (\%) & $166(38 \cdot 2)$ & & $(32 \cdot 2)$ & & $(34 \cdot 3)$ & & (38.9) & & 35.3) & \\
\hline Multivariate-adjusted OR $1^{*}$ & 1.00 & 0.80 & $0.60-1.07$ & 0.91 & $0.67-1.22$ & $1 \cdot 10$ & $0.80-1.50$ & 0.88 & $0.64-1.23$ & 0.992 \\
\hline Multivariate-adjusted OR $2 \dagger$ & 1.00 & 0.85 & $0.63-1.14$ & 0.91 & $0.67-1.24$ & $1 \cdot 18$ & $0.86-1.63$ & 0.95 & $0.67-1.34$ & 0.657 \\
\hline Multivariate-adjusted OR 3‡ & 1.00 & 0.82 & $0.59-1.14$ & 0.86 & $0.63-1 \cdot 19$ & 1.04 & $0.70-1.57$ & 0.78 & $0.50-1.23$ & 0.473 \\
\hline Criterion: IMT $\geq 1.0 \mathrm{~mm}$ & & & & & & & & & & \\
\hline$n$ & 912 & & 13 & & 12 & & 13 & & 14 & \\
\hline Subjects with IMT $\geq 1.0(\%)$ & $52(5 \cdot 7)$ & & $(4 \cdot 3)$ & & (3.9) & & $(4.4)$ & & $(1.9)$ & \\
\hline Multivariate-adjusted OR $1^{*}$ & 1.00 & 0.79 & $0.51-1.22$ & 0.83 & $0.53-1.30$ & 1.00 & $0.65-1.55$ & 0.43 & $0.25-0.77$ & 0.020 \\
\hline Multivariate-adjusted OR 2† & 1.00 & 0.86 & $0.55-1.34$ & 0.91 & $0.57-1.43$ & $1 \cdot 10$ & $0.70-1.72$ & 0.51 & $0.29-0.91$ & 0.092 \\
\hline Multivariate-adjusted OR 3‡ & 1.00 & 0.83 & $0.51-1.33$ & 0.77 & $0.45-1.33$ & 0.82 & $0.46-1.48$ & 0.34 & $0.16-0.70$ & 0.005 \\
\hline Subjects aged $<65$ years & & & & & & & & & & \\
\hline$n$ & 477 & & 03 & & 51 & & 15 & & 59 & \\
\hline Subjects with IMT $\geq 1.0(\%)$ & $9(1.9)$ & & 1.6) & & (1.6) & & $(2 \cdot 3)$ & & $0 \cdot 8)$ & \\
\hline Multivariate-adjusted OR $1^{*}$ & 1.00 & 0.85 & $0.32-2 \cdot 24$ & 1.01 & $0.39-2.59$ & 1.28 & $0.54-3.00$ & 0.49 & $0.16-1.48$ & 0.372 \\
\hline Multivariate-adjusted OR $2 \dagger$ & 1.00 & 0.96 & $0.35-2.62$ & $1 \cdot 13$ & $0.42-3.02$ & 1.47 & $0.59-3.66$ & 0.62 & $0.19-1.96$ & $0 \cdot 640$ \\
\hline Multivariate-adjusted OR $3 \ddagger$ & 1.00 & 0.95 & $0 \cdot 32-2 \cdot 81$ & 0.94 & $0.29-2.98$ & $1 \cdot 13$ & $0.34-3.76$ & 0.43 & $0.10-1.83$ & 0.227 \\
\hline Subjects aged $\geq 65$ years & & & & & & & & & & \\
\hline$n$ & 435 & & 10 & & 361 & & 98 & & 55 & \\
\hline Subjects with IMT $\geq 1.0(\%)$ & $43(9.9)$ & & $(7 \cdot 6)$ & & $(7 \cdot 5)$ & & (8.7) & & $(4 \cdot 7)$ & \\
\hline Multivariate-adjusted OR $1^{*}$ & 1.00 & 0.78 & $0.48-1.27$ & 0.78 & $0.47-1.30$ & 0.90 & $0.53-1.51$ & 0.42 & $0.22-0.83$ & 0.029 \\
\hline Multivariate-adjusted OR 2† & 1.00 & 0.83 & $0.50-1.36$ & 0.84 & $0.50-1.42$ & 0.99 & $0.58-1.68$ & 0.47 & $0.24-0.94$ & 0.082 \\
\hline Multivariate-adjusted OR $3 \ddagger$ & 1.00 & 0.83 & $0.49-1.42$ & 0.75 & $0.40-1.40$ & 0.77 & $0.39-1.52$ & 0.33 & $0.14-0.77$ & 0.013 \\
\hline
\end{tabular}


did not show any significant associations, which can be attributed to the low cut-off value for subclinical atherosclerosis for the elderly subjects. Since IMT increases with age, the low cut-off for subclinical atherosclerosis was not appropriate for detecting the effect of dietary $\mathrm{Zn}$ among the elderly subjects. When IMT $\geq 1$ was used to determine the OR, a significant inverse relationship between $\mathrm{Zn}$ intake and subclinical atherosclerosis was found only among the elderly subjects aged $\geq 65$ years (5th $v$. 1st quintile, OR $0.33,95 \%$ CI $0.14,0.77, P$ for trend=0.013). Since the number of subjects with IMT $\geq 1$ was small among the middle-aged adult subjects, any significant association was not found in the middle-aged adult subjects. Taken together, these results suggest that adequate dietary $\mathrm{Zn}$ intake may have a beneficial effect on the risk of atherosclerosis among the middle-aged adult and elderly populations, and different criteria for subclinical atherosclerosis may be needed between age groups.

Limited epidemiological studies have examined the relationship between $\mathrm{Zn}$ intake and atherosclerosis. Dietary $\mathrm{Zn}$ intake was positively correlated with serum $\mathrm{Zn}$ levels in cross-sectional studies ${ }^{(10,32)}$, and lower dietary $\mathrm{Zn}$ intake and lower concentrations of serum $\mathrm{Zn}$ were associated with a higher prevalence of $\mathrm{CHD}^{(10,12)}$ or an increased cardiovascular mortality ${ }^{(33)}$. Lower serum $\mathrm{Zn}$ concentrations have been reported in patients with various forms of coronary artery diseases in case-control studies ${ }^{(13,34-36)}$.

Several potential mechanisms may account for the cardiovascular benefits of $\mathrm{Zn}^{(6,8,9,37-43)}$. Atherogenesis involves the oxidation of LDL and its uptake into macrophages, and apoptosis of endothelial cells. Zn ions inhibited LDL oxidation by macrophages and endothelial cells ${ }^{(6)}$. The activity of caspase enzymes involved in apoptotic pathways was inhibited by $\mathrm{Zn}^{(8,9)}$. $\mathrm{Zn}$ deficiency increased apoptotic cell death induced by linoleic acid and TNF- $\alpha$, and supplementation of $\mathrm{Zn}$ attenuated apoptosis ${ }^{(37)}$.

$\mathrm{NO}$ is an endogenous signalling molecule produced by NO synthase. NO plays a substantial role in platelet and leucocyte function in human subjects. Several studies have suggested that NO can inhibit leucocyte adhesion through various mechanisms ${ }^{(38-40)}$. Zn plays a key role in endothelial NO synthase function by stabilising a dimer of two subunits of NO synthase ${ }^{(41)}$. Zn deficiency can reduce the activity of NO synthase, which causes a change in NO production. Changes in NO production are associated with the development of atherosclerosis $^{(42)}$. Indeed, $\mathrm{NO}$ is involved in $\mathrm{Zn}$ release from proteins by thiol nitrosylation ${ }^{(43)}$.

However, in the case-control studies conducted by Iskra et al. ${ }^{(14,15)}$, serum concentrations of $\mathrm{Zn}$ in individuals with atherosclerosis obliterans were higher than those in the healthy control groups. Even if the present findings reflect a causal relationship between $\mathrm{Zn}$ in food and atherosclerosis, this would not imply that the same amount or more $\mathrm{Zn}$ in supplements would have the same effect. High dose of $\mathrm{Zn}$ supplements $(\geq 50 \mathrm{mg}$ ) induced a decline in plasma HDLcholesterol concentrations in healthy young males ${ }^{(44-46)}$, which demonstrates that a high dose of $\mathrm{Zn}$ supplementation may induce an atherogenic lipoprotein profile. The tolerable upper intake levels of $\mathrm{Zn}$ for Koreans and Americans are $35^{(25)}$ and $40 \mathrm{mg} / \mathrm{d}^{(47)}$, respectively. Therefore, the role of $\mathrm{Zn}$ in $\mathrm{CHD}$ needs to be investigated further.
There are several limitations to the present study which need to be considered when interpreting the findings. First, convenience sampling may preclude generalisation of the results in the present study. Secondly, since this was a cross-sectional study, we cannot conclude causality of $\mathrm{Zn}$ intake for subclinical atherosclerosis. Thirdly, there were no subjects who took $\mathrm{Zn}$ supplement on a regular basis, and a total of 269 subjects $(5.9 \%)$ answered that 'they are taking multivitamin supplements', but most of the subjects could not remember the brand names of the multivitamins. Therefore, $\mathrm{Zn}$ intake from supplement was not considered. Fourthly, during the assessment of dietary $\mathrm{Zn}$ status, the bioavailability of $\mathrm{Zn}$ should be taken into account ${ }^{(48)}$. Phytate is a major inhibitory factor for $\mathrm{Zn}$ absorption, and phytate is present in whole grains, cereals and legumes. The phytate: $\mathrm{Zn}$ molar ratio has been used in several studies to predict the inhibitory effect of phytate on the bioavailability of $\mathrm{Zn}^{(26,48,49)}$. However, due to a lack of information on the phytate content of foods in the Korean Food Composition Table, the inhibitory effect of phytate on the bioavailability of $\mathrm{Zn}$ was not taken into account in the present study. Finally, despite the lack of a reliable and specific index, $\mathrm{Zn}$ status of the subjects needs to be assessed by biomarkers such as plasma and/or erythrocyte $\mathrm{Zn}$ concentrations as well as dietary intake, which was not done in the present study ${ }^{(50)}$.

To date, this is the first epidemiological study to determine the relationship between dietary $\mathrm{Zn}$ intake and IMT, an indicator of subclinical atherosclerosis. Among the rural middleaged adult and elderly populations in Korea, inadequate intake of $\mathrm{Zn}$ was related to high IMT and high risk of subclinical atherosclerosis. The present findings suggest that adequate intake of $\mathrm{Zn}$ may have a beneficial effect in reducing the risk of atherosclerosis. Further studies are necessary to examine these findings in prospective studies.

\section{Acknowledgements}

The present study was supported by the Korea Centers for Disease Control and Prevention (grants 2004-347-6111-213, 2005-347-2400-2440-215, 2006-347-2400-2440-215 and 2007 0308455-00). The authors' responsibilities are as follows: B. Y. C., B.-Y. C., S.-S. K., Y.-H. L. and M. K. K. designed the overall study and oversaw the data collection; Y. J. Y. and M. K. K. conducted the statistical analysis and wrote the manuscript draft; P. S. P. and M. K. K. contributed to dietary data collection and B. Y. C., B.-Y. C., S.-S. K., Y.-H. L., P. S. P. and M. K. K. provided critical reviews. None of the authors has any personal or financial conflicts of interest.

\section{References}

1. Chan YH, Lau KK, Yiu KH, et al. (2007) Isoflavone intake in persons at high risk of cardiovascular events: implications for vascular endothelial function and the carotid atherosclerotic burden. Am J Clin Nutr 86, 938-945.

2. Ellingsen I, Hjerkinn EM, Seljeflot I, et al. (2008) Consumption of fruit and berries is inversely associated with carotid atherosclerosis in elderly men. Br J Nutr 99, 674-681.

3. Merchant AT, Kelemen LE, de Koning L, et al. (2008) Interrelation of saturated fat, trans fat, alcohol intake, and subclinical atherosclerosis. Am J Clin Nutr 87, 168-174. 
4. He K, Liu K, Daviglus ML, et al. (2008) Intakes of long-chain $n-3$ polyunsaturated fatty acids and fish in relation to measurements of subclinical atherosclerosis. Am J Clin Nutr 88, 1111-1118.

5. Powell SR (2000) The antioxidant properties of zinc. J Nutr 130, 1447S-1454S

6. Wilkins GM \& Leake DS (1994) The oxidation of low density lipoprotein by cells or iron is inhibited by zinc. FEBS Lett $\mathbf{3 4 1}$, $259-262$.

7. Witztum JL \& Steinberg D (1991) Role of oxidized low density lipoprotein in atherogenesis. J Clin Invest 88, 1785-1792.

8. Perry DK, Smyth MJ, Stennicke HR, et al. (1997) Zinc is a potent inhibitor of the apoptotic protease, caspase-3. A novel target for zinc in the inhibition of apoptosis. J Biol Chem 272, 18530-18533.

9. Truong-Tran AQ, Carter J, Ruffin RE, et al. (2001) The role of zinc in caspase activation and apoptotic cell death. Biometals 14, 315-330.

10. Singh RB, Niaz MA, Rastogi SS, et al. (1998) Current zinc intake and risk of diabetes and coronary artery disease and factors associated with insulin resistance in rural and urban populations of North India. $J$ Am Coll Nutr 17, 564-570.

11. Lee DH, Folsom AR, Jacobs DR, et al. (2005) Iron, zinc, and alcohol consumption and mortality from cardiovascular diseases: the Iowa Women's Health Study. Am J Clin Nutr 81, 787-791.

12. Alissa EM, Bahjri SM, Ahmed WH, et al. (2006) Trace element status in Saudi patients with established atherosclerosis. J Trace Elem Med Biol 20, 105-114.

13. Ghayour-Mobarhan M, Taylor A, Kazemi-Bajestani SM, et al. (2008) Serum zinc and copper status in dyslipidaemic patients with and without established coronary artery disease. Clin Lab 54, 321-329.

14. Iskra M, Patelski J \& Majewski W (1997) Relationship of calcium, magnesium, zinc and copper concentrations in the arterial wall and serum in atherosclerosis obliterans and aneurysm. J Trace Elem Med Biol 11, 248-252.

15. Iskra M \& Majewski W (2000) Copper and zinc concentrations and the activities of ceruloplasmin and superoxide dismutase in atherosclerosis obliterans. Biol Trace Elem Res 73, 55-65.

16. de Groot E, Hovingh GK, Wiegman A, et al. (2004) Measurement of arterial wall thickness as a surrogate marker for atherosclerosis. Circulation 109, III33-III38.

17. O'Leary DH, Polak JF, Kronmal RA, et al. (1999) Carotidartery intima and media thickness as a risk factor for myocardia infarction and stroke in older adults. Cardiovascular Health Study Collaborative Research Group. $N$ Engl J Med 340, $14-22$.

18. Bots ML, Hoes AW, Koudstaal PJ, et al. (1997) Common carotid intima-media thickness and risk of stroke and myocardial infarction: the Rotterdam Study. Circulation 96, $1432-1437$.

19. Friedewald WT, Levy RI \& Fredrickson DS (1972) Estimation of the concentration of low-density lipoprotein cholesterol in plasma, without use of the preparative ultracentrifuge. Clin Chem 18, 499-502.

20. Ahn Y, Kwon E, Shim JE, et al. (2007) Validation and reproducibility of food frequency questionnaire for Korean genome epidemiologic study. Eur J Clin Nutr 61, 1435-1441.

21. The Korean Nutrition Society (2000) Food composition table. In Recommended Dietary Allowances for Koreans, 7th ed. Seoul: The Korean Nutrition Society.

22. Howard G, Sharrett AR, Heiss G, et al. (1993) Carotid artery intimal-medial thickness distribution in general populations as evaluated by B-mode ultrasound. ARIC Investigators. Stroke 24, 1297-1304.
23. Denarie N, Gariepy J, Chironi G, et al. (2000) Distribution of ultrasonographically-assessed dimensions of common carotid arteries in healthy adults of both sexes. Atherosclerosis 148, 297-302.

24. Simon A, Gariepy J, Chironi G, et al. (2002) Intima-media thickness: a new tool for diagnosis and treatment of cardiovascular risk. J Hypertens 20, 159-169.

25. The Korean Nutrition Society (2005) Dietary Reference Intakes for Koreans. Seoul: The Korean Nutrition Society.

26. Ma G, Li Y, Jin Y, et al. (2007) Assessment of intake inadequacy and food sources of zinc of people in China. Public Health Nutr 10, 848-854.

27. Andriollo-Sanchez M, Hininger-Favier I, Meunier N, et al. (2005) Zinc intake and status in middle-aged and older European subjects: the ZENITH study. Eur J Clin Nutr 59, S37-S41.

28. Ma J \& Betts NM (2000) Zinc and copper intakes and their major food sources for older adults in the 1994-96 continuing survey of food intakes by individuals (CSFII). J Nutr 130, $2838-2843$.

29. Moshfegh A, Goldman J \& Cleveland L (2005) What We Eat in America, NHANES 2001-2002; Usual Nutrient Intakes from Food Compared to Dietary Reference Intakes. Washington, DC: U.S. Department of Agriculture, Agricultural Research Service.

30. Chambless LE, Heiss G, Folsom AR, et al. (1997) Association of coronary heart disease incidence with carotid arterial wall thickness and major risk factors: the Atherosclerosis Risk in Communities (ARIC) Study, 1987-1993. Am J Epidemiol 146, 483-494

31. Buil-Cosiales P, Irimia P, Berrade N, et al. (2008) Carotid intima-media thickness is inversely associated with olive oil consumption. Atherosclerosis 196, 742-748.

32. Ghayour-Mobarhan M, Taylor A, New SA, et al. (2005) Determinants of serum copper, zinc and selenium in healthy subjects. Ann Clin Biochem 42, 364-375.

33. Reunanen A, Knekt P, Marniemi J, et al. (1996) Serum calcium, magnesium, copper and zinc and risk of cardiovascular death. Eur J Clin Nutr 50, 431-437.

34. Kazemi-Bajestani SM, Ghayour-Mobarhan M, Ebrahimi M, et al. (2007) Serum copper and zinc concentrations are lower in Iranian patients with angiographically defined coronary artery disease than in subjects with a normal angiogram. J Trace Elem Med Biol 21, 22-28.

35. Martin-Lagos F, Navarro-Alarcon M, Terres-Martos C, et al. (1997) Serum copper and zinc concentrations in serum from patients with cancer and cardiovascular disease. Sci Total Environ 204, 27-35.

36. Kerkeni M, Added F, Ben Farhat M, et al. (2008) Hyperhomocysteinaemia and parameters of antioxidative defence in Tunisian patients with coronary heart disease. Ann Clin Biochem 45, 193-198.

37. Meerarani P, Ramadass P, Toborek M, et al. (2000) Zinc protects against apoptosis of endothelial cells induced by linoleic acid and tumor necrosis factor alpha. Am J Clin Nutr 71, 81-87.

38. Freedman JE \& Loscalzo J (2002) Platelet-monocyte aggregates: bridging thrombosis and inflammation. Circulation 105, 2130-2132.

39. Kubes P, Suzuki M \& Granger DN (1991) Nitric oxide: an endogenous modulator of leukocyte adhesion. Proc Natl Acad Sci U S A 88, 4651-4655.

40. Kubes P (1995) Polymorphonuclear leukocyte-endothelium interactions: a role for pro-inflammatory and anti-inflammatory molecules. Can J Physiol Pharmacol 71, 88-97.

41. Zou MH, Shi C \& Cohen RA (2002) Oxidation of the zincthiolate complex and uncoupling of endothelial nitric oxide synthase by peroxynitrite. J Clin Invest 109, 817-826. 
42. Anderson TJ (2003) Nitric oxide, atherosclerosis and the clinical relevance of endothelial dysfunction. Heart Fail Rev 8, 71-86.

43. Beattie JH \& Kwun IS (2004) Is zinc deficiency a risk factor for atherosclerosis? Br J Nutr 91, 177-181.

44. Chandra RK (1984) Excessive intake of zinc impairs immune responses. JAMA 252, 1443-1446.

45. Hooper PL, Visconti L, Garry PJ, et al. (1980) Zinc lowers highdensity lipoprotein-cholesterol levels. JAMA 244, 1960-1961.

46. Black MR, Medeiros DM, Brunett E, et al. (1988) Zinc supplements and serum lipids in young adult white males. Am J Clin Nutr 47, 970-975.

47. Institute of Medicine (2001) Dietary Reference Intakes for Vitamin A, Vitamin K, Arsenic, Boron, Chromium, Copper,
Iodine, Iron, Manganese, Molybdenum, Nickel, Silicon, Vanadium, and Zinc. Washington DC: Institute of Medicine.

48. World Health Organization (1996) Trace Elements in Human Nutrition and Health. Geneva: WHO.

49. Turnlund JR, King JC, Keyes WR, et al. (1984) A stable isotope study of zinc absorption in young men: effects of phytate and alpha-cellulose. Am J Clin Nutr 40, 1071-1077.

50. Neggers YH, Goldenberg RL, Tamura T, et al. (1997) Plasma and erythrocyte zinc concentrations and their relationship to dietary zinc intake and zinc supplementation during pregnancy in low-income African-American women. $J$ Am Diet Assoc 97, 1269-1274. 